\title{
Estimation of the effect of dilution due to milk yield on milk somatic cell count across cow parities
}

S.J. More ${ }^{3}$, K O'Sullivan ${ }^{2}$, B O'Brien ${ }^{3}$, D.P. Berry ${ }^{3}$, P.T. Kelly ${ }^{1}$

${ }^{1}$ Moorepark Dairy Production Research Centre, Cork, Ireland

${ }^{2}$ School of Agriculture, Food Science and Veterinary Medicine, University College Dublin, Dublin, Ireland

${ }^{3}$ Department of Statistics, School of Mathematical Sciences, University College Cork, Cork, Ireland

Email: paddy.kelly@teagasc.ie

Introduction Subclinical mastitis is one of the most costly diseases in dairy cattle. However previously reported costs may have been over-estimated as a consequence of the dilution effect of milk yield on somatic cell count (SCC) (Green et al., 2006). Some adjustment of SCC for the effect of dilution has recently been made (Green et al., 2006), but without considering whether differences in milk yield and SCC exist among parities. The objective of the current study was to investigate the association between SCC and milk yield as well as calculating the dilution estimates of SCC due to increased milk yield for individual parities on grass based dairy production systems

Material and methods A total of 235,163 test day records from 23,791 cows in 366 Irish milk recorded herds between the years 2003 and 2005 were included in analysis. Herds with less then 10 cows milk recorded in a year were removed and only test-days between 5 and 305 days post-calving were retained. The association between test-day milk yield and test-day SCC was calculated within parity after pre-adjusting test-day SCC by using one of four methods (1.1 to 1.4) as described by Green et al. (2006). Method 1.1. there was no pre-adjustment of SCC. Method 1.2 pre-adjusted SCC $=$ SCC divided by corresponding SCC dilution estimate. The mean SCC for milk yield categories 10 to 20,21 to 30,31 to 40 and >41 litres was divided by the mean SCC for milk yield category 10 to 20 litres. This was done for each SCC category $(<51,51$ to 100 , 101 to 200,201 to 300,301 to 400,401 to $1000, \geq 1001$ cells $/ \mathrm{mL}$ ) separately to generate a total of 28 dilution estimates. Method 1.3 pre-adjusted $\mathrm{SCC}=\mathrm{SCC} *$ milk yield/mean milk yield for each parity. Method 1.4 pre-adjusted $\mathrm{SCC}=\mathrm{SCC}+(-$ regression coefficient of SCC on milk yield*milk yield). Within parity, a mixed model was developed where the data only included test days SCC of $<50,000$ cells $/ \mathrm{mL}$, as these animals were presumed uninfected. SCC was the dependent variable and cow was included as a random effect. Herd and calving month were included as fixed effects and the regression on milk yield was estimated. The association between milk yield and pre-adjusted SCC was estimated, within parity, using linear mixed models with milk yield as the dependent variable. Fixed effect were days in milk (DIM) and exponential $\left(\mathrm{DIM}^{-0.05}\right)$ (Wilmink, 1987; Green et al., 2006). Confounding effects forced into each of the models as cow level fixed effects were farm $(\mathrm{n}=366)$ and calving month (January to December).

Results Mean SCC was 175,084, 198,274, 242,300, 286,218 and 348,485 cells $/ \mathrm{mL}$, for parities 1 to 5, respectively. Mean milk yield was 20.4, 23.3, 24.8, 25.3 and 25.3 litres in parity 1 to 5 , respectively. When there was no pre-adjustment of SCC for milk yield (Method 1.1), a test day milk loss of 1.43, 2.08, 2.59, 2.56 and 2.62 litres was associated with an increase of SCC category from $<51$ cells $/ \mathrm{mL}$ to $>400$ cells $/ \mathrm{mL}$ in parity 1 to 5 animals, respectively. When Method 1.2 was used to pre-adjust SCC a smaller reduction in test day milk yield of 1.40, 2.00, 2.43, 2.39 and 2.47 litres (parity 1 to 5 animals, respectively) was observed with an increase of SCC category from $<51$ cells $/ \mathrm{mL}$ to $>400$ cells $/ \mathrm{mL}$. When Method 1.3 was used to pre-adjust SCC an increase in test day milk yield of $0.97,0.60,0.17,0.24$ and 0.30 litres for parity 1 to 5 animals, respectively was observed with an increase of SCC category from $<51$ cells $/ \mathrm{mL}$ to $>400$ cells $/ \mathrm{mL}$. When Method 1.4 was used to pre-adjust SCC a reduction in test day milk yield of 1.29,1.77, 2.24, 2.20 and 2.31 litres for parity 1 to 5 animals, respectively was observed with an increase of SCC category from $<51$ cells $/ \mathrm{mL}$ to $>400$ cells $/ \mathrm{mL}$. Regression coefficients ( $($ ) used in Method 1.4 were $-0.274,-0.442,-0.445,-0.520$ and -0.441 litres for parities 1 to 5 , respectively. For example if the adjustment methods were applied to two cows with a SCC of 400,000 cells $/ \mathrm{mL}$ with a milk yield of 15 and 25 litres, the SCC would be 400,000 and 384,615 cells/mL for Method 1.2, 294,118 and 490,196 cell/mL for Method 1.3 and 400,004 and 400,007 cells $/ \mathrm{mL}$ for Method 1.4. Thus it is possible that SCC is over adjusted in Method 1.3. The dilution estimates in the study changed the association between SCC and milk yield; with a decrease in milk loss compared to milk loss associated with no SCC pre-adjustment (Method 1.1) of 3, 5, 6, 7 and 6\% (parities 1 to 5, respectively) following the first SCC pre-adjustment (Method 1.2), and 10,15, 13,14 and 12\% (parities 1 to 5, respectively) for the third preadjustment (Method 1.4). For Method 1.3 there was a decrease in the test day milk loss associated with increasing SCC of $167,129,107,109$ and $111 \%$ (parities 1 to 5 , respectively). Methods 1.1 to 1.4 were statically significant $(\mathrm{P}<0.05)$.

Conclusions Two of the SCC dilution estimates used in the present study (Method 1.2 and 1.4) showed an increased SCC was associated with reduced milk yield. The remaining dilution estimate (Method 1.3) showed an increased SCC was associated with an increased milk yield. When the dilution estimates were investigated Method 1.2 had the best fit (lowest $\log$ likelihood value) to count for dilution in a grass based milk production system. The results from the study can be used to quantify the changes in milk production for different cow parities due to increased SCC in grass based seasonal production systems. The dilution estimates developed in the study can also be used to generate accurate estimates of milk yield loss due to SCC and thus economic costs of increased SCC.

\section{References}

Green, L.E., Schukken, Y.H. and Green, M.J. 2006. Preventive Veterinary Medicine. 76, 74-89

Wilmink, J.B.M. 1987. Livestock Production Science. 16, 335-353 